\title{
A Nod to the Past and a Look to the Future
}

\author{
Elaine M. Rutkowski \\ California State University, Fullerton
}

(C) 2016 Californian Journal of Health Promotion. All rights reserved.

"Health promotion, or the process of helping healthy people stay healthy, is a growing and exciting field (Brown, 2003). It was thirteen years ago that Kristine Brown, Associate Editor, made this opening statement in the first issue of the Californian Journal of Health Promotion (CJHP). She challenged the readers of this first edition, "to recognize and value differences in our educational preparation, professional experience, research interests and expectations (Brown, 2003). Here we are in 2016, 42 issues later, and we believe that this challenge has not only been met, but likely exceeds the expectations of the editors who published the early issues of this journal.

There are many, many individuals who have contributed to the success of the Californian Journal of Health Promotion. This publication has been "housed" at two California State University locations: Chico and Fullerton. Throughout the past 13 years, contributions at all levels of production from editors, associate editors, reviewers and authors have been without remuneration. All parties have supported this journal knowing that "payment" is the satisfaction of furthering the field of health promotion through collaboration and collegial dialogue. The hours spent in authoring, reviewing and editing are fueled by the passion of individuals working to share with readers the most current interventions for achieving and maintaining the highest level of health in our communities.

During California education's difficult financial times, there has been limited support to maintain this publication as an "open access" on-line journal. There are no subscription revenues to pay for the costs incurred from "housing" a journal. Currently, the Californian Journal of Health Promotion continues with some support at the departmental and college level at CSUF. We have recently added two editors with the knowledge that the journal is growing in the numbers of manuscripts received. The timely assignment of associate editors and reviewers, as a result of such growth, will benefit with these additional editors. Our desire to reach two goals (1) to achieve an "impact factor" and (2) to create infrastructure to offer "continuing education" opportunities are in our future with this influx of quality manuscripts.

Our future has been described by Dr. Laurie Roades, Dean, College of Health and Human Development, CSUF, as she notes, "We are fortunate to have such an avenue available to authors, and researchers and the public alike who are able to access cuttingedge research findings in an open access format at no cost. We look forward to the continued growth and contributions of the CJHP and to an even wider audience for the journal in the future” (personal communication, April, 26, 2016).

The editors of CJHP have a deep commitment to the ongoing work of the Californian Journal of Health Promotion. We are very grateful for each of our colleagues who have continued to offer their expertise during the manuscript development and reviewing process. The mission to grow as a scholarly, peer-reviewed, online journal that is devoted to health education and health promotion practice, research, and teaching, depends fully on the support of our 
associate editors and reviewers. We want to thank each of you for your shared passion and commitment. We are excited to look ahead with the realization that the $C D H P$ will continue to address gaps in health promotion activities through the work of multiple disciplines who share research interests and expectations.

\title{
Reference
}

Brown, K. (203) Editorial: maintaining professional identity \& integrity within the field of health promotion. Californian Journal of Health Promotion 1 (1), iv.

\author{
$\underline{\text { Author Information }}$ \\ Elaine M. Rutkowski, PhD, RN, CNS, PHN \\ California State University, Fullerton \\ School of Nursing \\ 800 N. State College Blvd. \\ Fullerton, CA 92831 \\ erutkowski@fullerton.edu \\ 657/278-3308
}

* corresponding author 